\title{
Anti-aging amino acids in Euryale ferox (Salisb.): a review
}

\begin{abstract}
Proteins of Euryale have a unique assemblage of different amino acids which act as medicinal ingredients for anti aging properties in human cell. Most of the important amino acids present in Euryale are leusine isoleucine, cysteine, methionine, glutamine and arginine. The amino acids arginine and methionine are the precursors of creatine which is essential for beautiful skin nails and hairs. Taurine synthesized from cysteine reduces diabetic effect in cell. Arginine which produces nitric oxide within the cell increases elasticity of arteries and veins thereby increases blood flow. Other amino acids like iso-leucine and proline help in growth and development of the body. The most powerful antioxidants have been found within amino acids, which can remove the free radical intermediates and terminate chain reactions and fight against aging and are readily available in certain foods, especially, like Euryale.
\end{abstract}

Volume 8 Issue I - 2018

\author{
BR Jana, Md Idris \\ ICAR-RCER, Research Centre for Makhana, Darbhanga, India
}

Correspondence: BR Jana, Former Scientist ICAR-RCER, Research Center Ranchi, Jharkhand-8340 I0, India, Email brjana.ars@gmail.com

Received: December 27, 2017 | Published: February 01, 2018

Keywords: Euryale, amino acids, functions, human health

\section{Introduction}

Since ancient times, beautiful skin, firm nails and shiny hairs which look good and live young, has had a strong desire for humans. To maintain health and natural beauty as long as possible and to delay the aging process, continuous supply of some nutrients is necessary in the body. Our metabolism is reflected on the skin, which is sensitive to any change that happens. From inside of a body, the right amino acid mix acts like a repair treatment for skin infection, allergy, coarse -pores and sagginess. Studies stressed the importance amino acids to keep the hair healthy and the skin firms were confirmed by different researchers. ${ }^{1-3}$ Apart from giving anti-oxidant to cells, amino acids supply nutrients to nourish the skin, hair and nails within the body which strengthens higher connective tissue and keeps the skin smooth and elastic, the nails firm and the hair strong and paved the way for attractive looking for men and women and finally retards aging.

The Euryale is wonderful medicinal plant from wet land ecosystem. It belongs to the family Euryladacae, The origin of the crop is tropical south East Asia particularly India and China. The nut of Euryale is the major source of protein carbohydrates, unsaturated fats. ${ }^{4,5}$ It contains appreciable amount of $\mathrm{Ca} \mathrm{Mg}$, and other micronutrients. ${ }^{6}$ It is also afair source of dietary fiber and act against constipation of seizarian baby. It is nice food for controlling B.P. Sugar, heart diseases and anemia ${ }^{7}$ and thereby increases fertility of men and women. The different kinds of aurvedic medicines are prepared from Euryale kernel powder. ${ }^{8}$ It has an important ingredient which is used to strengthen spleen and kidneys. It is nutritious and easily digested ${ }^{4,7}$ its medicinal properties lying on treating circulatory disorders. ${ }^{8}$ Appreciale amount of glumine/glutamic acid was also found in makhana raw (16.64\%) as well as makhana popped $(17.06 \%),{ }^{8}$ which has remarkable anti aging effect. As a very good immune stimulant Euryale raw powder or popped stimulated hormonal immunity and effective for women at post natal stage. ${ }^{9}$ It is effective against arthritis, impotence and premature aging. ${ }^{10}$ The present study aimed to reconsider different effects of amino acids and their influence in human health and caused for beneficial effect for long time normal living (Figures 1-4).

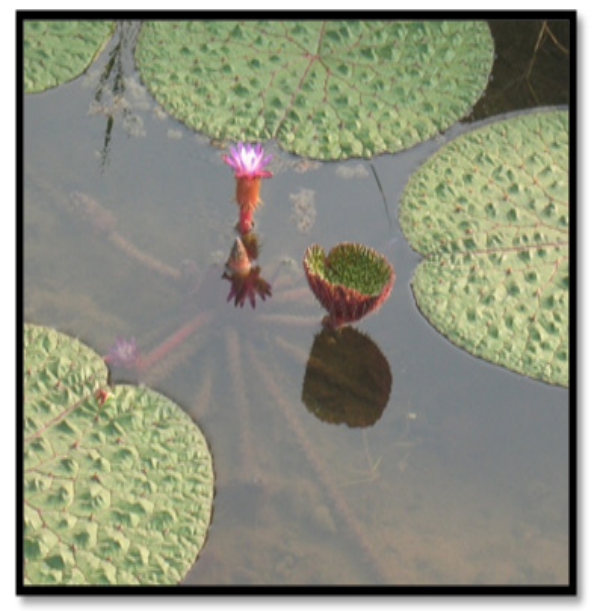

Figure I Euryale Plant.

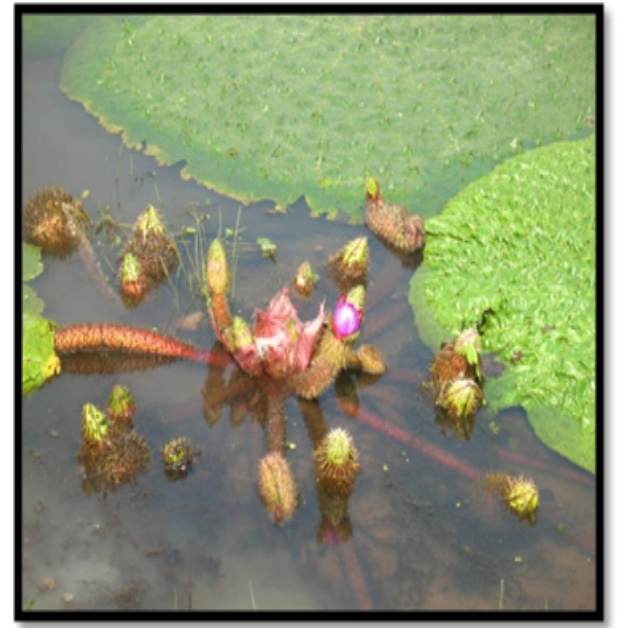

Figure 2 Euryale Fruits. 


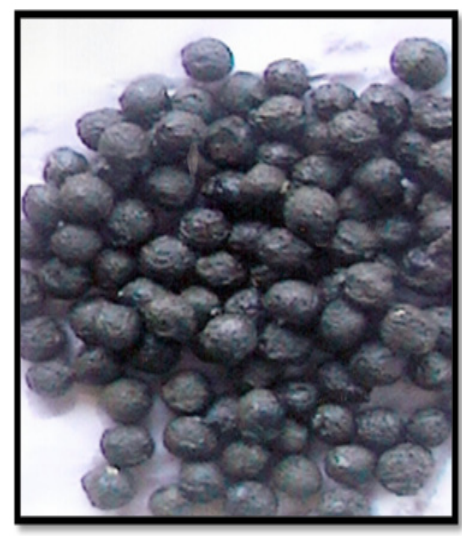

Figure 3 Euryale nuts.

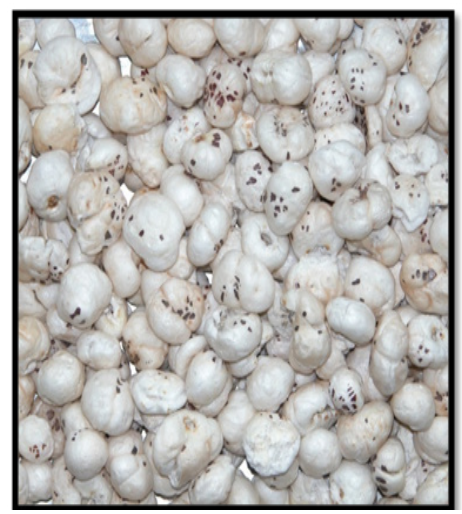

Figure 4 Popped Euryale.

\section{Materials and methods}

We have analyzed data regarding protein carbohydrates and macronutrients. The protein content of the nut is $11.16 \%$. Amino acid profile in relation to protein content in makhana is different from another nut like chashew and almond. The protein content was determined by Lowry method and carbohydrates by Anthrone method. ${ }^{11}$ The different authors determined the different amino acids composition in raw and popped makhana by using Colorimetric methods based on principle of Lambert and Beers law or using HPLC for quantitive determination after preparation of the samples by different chemical reagents. Data are recorded after comparing with standard curve. $\mathrm{N}(\%)$ by Kjedahl method ${ }^{12}$ and protein by amino acid analysis by colorimeter through Ninhydrin test were performed in present study. Dried samples $(1 \mathrm{~g})$ were digested with diacid mixture (HNO3: HClO4: 9:4). After digestion and extraction of samples, total $\mathrm{P}$ was determined with the vanodomolybdophosphoric acid yellowcolour method ${ }^{13}$ and total $\mathrm{K}$ and $\mathrm{Na}$ were determined with the flame photometric method. ${ }^{13}$ Water-soluble $\mathrm{Ca}$ and $\mathrm{Mg}$ were determined by the Versanate method. ${ }^{14}$ Water-soluble $\mathrm{Fe}, \mathrm{Mn}, \mathrm{Cu}$ and $\mathrm{Zn}$ were measured with an atomic absorption spectrophotometer (A Analyst 100, Perkin Elmer, Norwalk, CT, USA).

\section{Results and discussion}

The chemical constituents of raw Euryale $[\mathrm{g} / 100 \mathrm{~g}$ ) are moisture 11.82 , carbohydrates 75.04 , protein 11.16 fat 0.5 and total minerals like ca 0.27 ,phosphorus 0.28 amd iron 0.006 . The similar results were also found by the authors. ${ }^{15,16}$ With regard to nutritional value Euryale is good source of unique proteins and carbohydrates. In our present study protein content of the kernel was 11.16 percent (Table 1). This result was in accordance with the results of Jha et al., ${ }^{8}$ Shankar et al., ${ }^{17}$ Kumar et al., ${ }^{18}$ Kumar et al. ${ }^{19}$ In raw Euryale leucine and Isoleucine content was $8.34 \%$ and $4.18 \%$ but in popped there were $8.85 \%$ and $4.8 \% .{ }^{8}$ From the past study of, ${ }^{8}$ it was found that the arginine content of raw and popped Euryale were $15.19 \%$ and $16.07 \%$, respectively. In respect of glutamic acid content raw Euryale was $16.64 \%$ but popped Euryale had little bit higher amount $17.06 \%$ (Table 2). In human body, when glutamic acid, which is acidic, loses a hydrogen from its side chain, it becomes glutamate, with a side chain composed of $\mathrm{CH} 2 \mathrm{CH} 2 \mathrm{COO}$. Human body uses glutamic acid or glutamate for a variety of purposes. Their origin and reaction in body as follows:

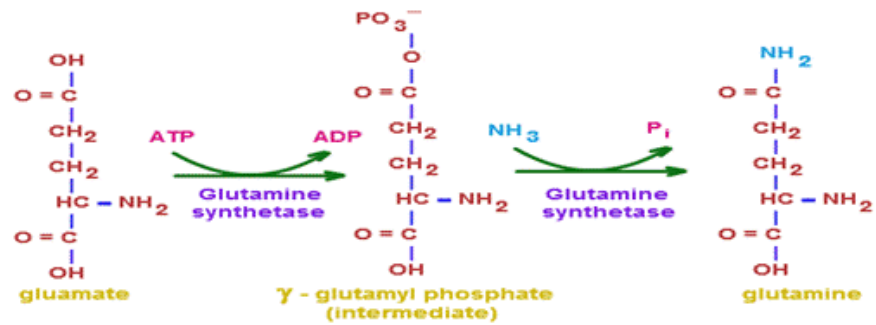

In the seed of Euryale ferox there was simple conversation from glutamate to glutamine and ultimately glutamic acid. The raw Euryale contains the maximum glutamic acid, which has positive impact on youth.

Table I Updated information of raw Euryale composition

\begin{tabular}{lllll}
\hline Constituents & $\mathbf{1 9 5 2 * *}$ & $\mathbf{2 0 I I *}$ & $\mathbf{2 0 1 6}$ & $\mathbf{2 0 1 7}$ \\
\hline Moisture \% & 12.8 & $10.7 \mathrm{I}$ & 34.7 & $1 \mathrm{I} .82$ \\
Carbohydrate\% & 76.9 & 70.77 & 57 & 75.04 \\
\% Protein & 9.7 & 11.02 & 7.2 & $1 \mathrm{I} .16$ \\
Fat\% & $\ldots$. & $0.4 \mathrm{I}$ & 0.3 & $0.5 \mathrm{I}$ \\
Phosphorus \% & $\ldots$. & 0.08 & 0.066 & 0.028 \\
Sulpher \% & $\ldots$. & 0.024 & $\ldots$. & 0.042 \\
Calcium \% & & 0.037 & 0.01 & 0.027 \\
Magnesium \% & $\ldots$ & 0.01 & $0.01 \mathrm{I}$ & 0.006 \\
Pottasium \% & $\ldots$ & 0.042 & 0.035 .6 & 0.037 \\
Iron \% & 1.4 & 0.004 & 0.008 & 0.006 \\
Ash\% & 0.4 & 0.418 & 0.3 & 0.62 \\
Total & $\ldots .$. & 93.525 & 99.59 & 99.3 \\
\hline
\end{tabular}

**CSIR (1952) 4 *Shankar et al. ${ }^{15}$ and Kumar et al., ${ }^{16}$ Kumar et al. (Swarna Vaidehi), ${ }^{17}$ Present study=2017. (Swarna vaidehi).

The leucine to isoleucine ratio and arginine +lysine to proline ratio of raw Euryale was observed as $1.9 \%$ and $7.6 \%$ in Tripura sample, respectively. In popped Euryale or makhana these values were 1.99\% and $4.74 \%$, respectably (Table 3 ). In our present study in whole starch N (\%) by kjedahl method was 1.57 and protein $\%$ by amino acid analysis was $10.72 \%$ (Table 4 ). The results were corroborated by Nath and Chakraborty. ${ }^{20}$ According to authors ${ }^{8}$ the essential amino acid index of raw and fried makhana was 93.63 and 89.97, respectively (Table 5). The sulpher containing amino acid like cystine and methionine in raw Euryale or makhana was $0.75 \%$ and $3.06 \%$ but 
in popped makhana these values were $1.21 \%$ and $2.95 \%$ (Table 2). so kernels of Euryale were the major source of glutamine, arginine, leucine and isoleucine and fair source of cystine and methionine and other amino acids which act as antioxidant as well as precursors of other long chain amino acids for normal health functions.

Table 2 Comparison of Protein and amino acid composition $(\mathrm{g} / \mathrm{l} 6 \mathrm{gN})$ of Euryale with norms of $\mathrm{FAO} / \mathrm{WHO}$

\begin{tabular}{llll}
\hline \multirow{2}{*}{ Amino acid } & Makhana & & FAO/W \\
\cline { 2 - 4 } & Raw (\%) & Fried (\%) & (1973) \\
\hline Lysine & 3.79 & 4.69 & 5.4 \\
Histidine & 3.15 & 3.12 & 2.5 \\
Arginine & 15.19 & 16.07 & 5.2 \\
Asparatic acid & 5.76 & 5.05 & 7.7 \\
Threonine & 3.34 & 3.51 & 4 \\
Serine & 5.05 & 5.64 & 7.7 \\
Glutamic acid & 16.64 & 17.06 & 14.7 \\
Proline & 4 & 3.24 & 10.7 \\
Glycine & 3.01 & 3.28 & 2.2 \\
Alanine & 5.5 & 5.84 & 6.1 \\
Valine & 5.18 & 5.49 & 5 \\
Cystine & 0.75 & 1.21 & - \\
Methionine & 3.06 & 2.95 & 3.5 \\
Isoleucine & 4.18 & 4.8 & 4 \\
Leucine & 8.34 & 8.85 & 7 \\
Tryosine & 6.38 & 2.91 & 3.05 \\
Phenylalanine & 5.78 & 6.12 & 3.05 \\
Tryptophan & n.d & n.d & 1 \\
Protein (\%) & 11.1 & 11.5 & 10 \\
\hline
\end{tabular}

Jha et al. ${ }^{8} \mathrm{~N} . \mathrm{d}$, not detected
Table 3 Comparative value of leucine to isoleucine and arginine + lysine proline ratios in foods

\begin{tabular}{lll}
\hline Feeds & $\begin{array}{l}\text { Leucinel } \\
\text { Isoleucine }\end{array}$ & $\begin{array}{l}\text { (Arginine+Lysine+ } \\
\text { Proline) }\end{array}$ \\
\hline FAO/WHO pattern & 1.75 & 0.99 \\
Rice & 1.66 & 4 \\
Wheat & 1.66 & 0.71 \\
Soya bean & 1.45 & 2.86 \\
Amaranth & 1.27 & 3.41 \\
Euryale Raw(Tripura ample) & 1.9 & 7.6 \\
Euryale Raw (Bihar sample) & 1.84 & 6.3 \\
Euryale Fried (Bihar sample) & 1.99 & 4.74 \\
\hline
\end{tabular}

Jha et al. ${ }^{8}$

\section{Creatine stimulates collagen production and skin functions}

Creatine derived from arginine and methionine plays an important role for healthy skin which are finally a part of carnitine. Creatin also plays an important role in energy metabolism of the cells in the body. Creatine provides the cells with energy and thereby supports the regeneration of connective tissue, cells and metabolism of the skin. As soon as arginine and carnitine form Creatine, natural skin functions are supported and the cells are stimulated to produce more collagen and elastin and repairing of DNA (damaged). In addition, Creatine can protect the cells from harmful substances, protects the connective tissue and is give desire firmness to skin (strong ligaments, tendons and cartilage). Creatine stimulates endogenous collagen production which increases storage of water. This phenomenon allows skin moistens, thicker, smooth, fresh and wrinkle-free appearance resulted in men and women beauty. ${ }^{21}$

Table 4 Chemical composition and properties of starch of Euryale ferox

\begin{tabular}{lllll}
\hline Determination & $\begin{array}{l}\text { Whole } \\
\text { starch }\end{array}$ & $\begin{array}{l}\text { Protein free } \\
\text { starch }\end{array}$ & $\begin{array}{l}\text { Whole starch (Present } \\
\text { study=PS) }\end{array}$ & Protein free starch (PS) \\
\hline Yield (\%) from seed meal & 52.5 & n.d & 59.55 & 52.02 \\
Moisture (\%) & 14.4 & 13.5 & 12.75 & 11.97 \\
Ash (\%) & 15 & 0.15 & 4.5 & 0.42 \\
N (\%) by kjedahl method & 1.36 & Nil & 1.57 & Nil \\
Protien (\%) by amino acid analysis & 7.32 & Trace & 10.72 & Trace \\
Total carbohydrate (\%) & 77.33 & 86.85 & 75.25 & 84.92 \\
Amylose (\%), Potentiometrically & n.d & 25.3 & 27.02 & 24.74 \\
Amylopectin (\%) with respect to amylose & n.d. & 74.7 & 74.95 & 74.62 \\
\hline
\end{tabular}

Nath et al. ${ }^{20}$ PS, present study 
Table 5 Comparative value of essential amino acid index (EAAI) and biologica value (BV) of foods

\begin{tabular}{llll}
\hline Feeds & EAAl & BV & CS(\% EGG) \\
\hline Rice & 82.88 & 68 & 54.93 \\
Wheat & 65.18 & 62.6 & 39.7 \\
Bengal gram & 81.55 & 68 & 53.33 \\
Soyabean & 85.59 & 50.7 & 52.6 \\
Amaranth & 57.72 & - & 40.93 \\
Euryale Fried & 89.97 & 55 & 56.57 \\
Euryale Raw & 93.63 & & 70
\end{tabular}

Jha et al. ${ }^{8}$

\section{Glutamine for firm skin and controls the acid-base balance in cell}

Amino acid glutamine supports the regulation of acid-base balance in the body. It is also important for the firm Skin..$^{22}$ In addition, a balanced diet is the precondition for healthy skin and shining appearance. The supply of vital nutrients and other important organic compounds slows the aging process of the skin and supports rebirth of cells. Free radical scavengers have played an important role in removing unwanted bio-chemicals from the cells. Glutamine, this substance is responsible for the production of proteins in the body reduces with the rise of age. In the absence of enough glutamine the body takes the necessary proteins from the muscles that seem to be aging. Glutamine retards the aging process, so it is often called the " Inner Fountain of Youth'. ${ }^{23}$

\section{Carnitine helps to produce energy from fat}

The amount of body fat goes up during aging. To keep fit Carnitine is essential because it controls body weight and helps in the transport of fatty acids because of energy burn. That is why it can often contribute to growth. Carnitine, better to say "fat burner" keep human as fit and well. ${ }^{24}$ Carnitine propels mitochondrial function and is synthesized from two essential amino acids lysine and methionine. By enhancing mitochondrial function, we can improve the biochemical processes in cell that tend to breakdown with age. Recent research has proved that carnitine elevates antioxidant activity, further contributing to antiaging activity within the body ${ }^{9}$ Several amino acids are considered to be essential nutrients for maintaining normal cardio-vascular function deficient that are associated with heart dysfunction. ${ }^{25,26}$ Because intra cellular taurine is depleted during the development of diabetes, ${ }^{27}$ the role of changes in the level of this amino acid has been indicated in diabetes-induced cellular abnormalities. It has been reported that taurine is a sulphur-containing amino acid that is most abundant in the cell. ${ }^{28}$ The biosynthetic capacity of taurine is very low in humans and, thus, diet is its major source in the body. ${ }^{27}$ Taurine has been demonstrated to exhibit a diverse range of biological actions including protection against ischemia-reperfusion injury, modulation of intracellular calcium concentration, and antioxidant, antiatherogenic and blood pressure-lowering effects. ${ }^{26}$

Arginine, another amino acid, has been proven to be a precursor to the synthesis of nitric oxide in almost all types of cells, and it is also believed to be associated with smooth cardiovascular function. ${ }^{29}$ Dietary intake of arginine remains the primary determinant of plasma arginine levels because the rate of arginine biosynthesis does not increase to compensate for its depletion or inadequate supply. ${ }^{30,31}$ It should also be noted that the lack of carnitine leads to secondary to diabetes, ${ }^{32-34}$ and exogenous carnitine has been shown to improve cardiac metabolism and function. ${ }^{35,36}$ Carnitine is mainly synthesized endogenously, and cardiac muscle contains relatively high carnitine concentrations and plays an important regulatory role in energy metabolism. ${ }^{32}$ Biosynthesis of taurine. In the pancreas via the Cysteine sulfuric acid pathways very less within the body. Dietary taurine has a blood cholesterol-lowering effect in young overweight adults and it is essential for cardiovascular function, and controls body weight and helps in function of the central nervous system and diabetes. ${ }^{37-39}$

\section{Amino acids and antioxidant activities}

Glutamate and aspartate are essential amino acids, apart from their protein function; they are also important chemical messengers in the brain involved in neurotransmission and act as antioxidant. ${ }^{40}$ Some amino acids act as antioxidant and remove the Reactive Oxygen Species from the cell. Cysteine, antioxidants act against biological systems subjected to oxidative stress in conditions such as inflammation and aging. ${ }^{41}$ Besides, cysteine, glutathione, lipoic acid also are potent antioxidant. In a comparison of the structure-function relationship among these sulfur-containing antioxidant compounds, dihydrolipoic acid is the most effective antioxidant. ${ }^{42}$ Enzymatic anti oxidant works by breaking down poly compounds and removing free radicals from the cell. In this reaction metal ion like copper, $\mathrm{Zn}$, manganese and iron act as cofactors of reactive enzymes. The main enzymatic antioxidants are Glutathione Peroxidase, Catalase and Superoxide Dismutase [SOD] in human cell which usually fight against oxidative stress and aging. ${ }^{43}$

\section{Conclusion}

Anti aging amino acids like glutamine, cystine methionine arginines are present in Euryale in higher concentration. Other amino acids for normal body function present in appreciable proportion in raw as well as popped Euryale. This review giving emphasis on amino acids present in Euryale provide a window for further research regarding nutritional importance and how to increase neutraceuticals in crops by the way of horticultural management practices.

\section{Acknowledgements}

Authors are very much thankful to National Medicinal Plant Board (New Delhi)for their sponsored project on bael and Central Institute for Arid Horticulture" Bikaner, India for technical guidelines as one of the consortia partners and lead centre.

\section{Conflict of interest}

The author declares no conflict of interest.

\section{References}

1. Saini R, Zanwar AA, Sachin L Badole. Arginine derived nitric oxide: key to healthy skin. Bioactive Dietary Factors and Plant Extracts in Dermatology. 2013. p. 73-82.

2. Evangeliou, A Vlassopoulos D. Carnitine metabolism and deficit-when supplementation is necessary? Curr Pharm Biotechnol. 2003;4(3):211219.

3. Reda E, D'Iddio S, Nicolai R, et al. The carnitine system and body composition. Acta Diabetol. 2003;40(Suppl 1):106-103. 
4. CSIR. The Wealth of India. New Delhi, India: CSIR Publication; 1952.

5. Singh AB, Arora RK. Wild edible plants of India. New Delhi, India: ICAR; 1978. 257 p.

6. Mishra RK, Jha Vidyanath, Dharai PV. Makhana editors. New Delhi, India: ICAR; 2003. p. 1-340.

7. Das S, Der P, Raychaudhuri U, et al. The effect of Euryale ferox Salisb. (Makhana), an herb of aquatic origin on myocardial ischemic repurfsion injury. Mol Cell Biochem. 2006;289(1-2):55-63.

8. Jha V, Barat GK, Jha UN. A Nutritional evaluation of Euryale ferox Salisb (Makhana). Journal of Food Science and Technology. 1991;8(5):326-328.

9. Puri A, Sahai R, Singh KL. Immunostimulant activity of dry fruits and plants materials used in Indian traditional medical system for mothers after child birth and invalids. J Ethnopharmacol. 2000;71 (1-2):89-92.

10. Mc Guffin M, Hobbs C, Upton R. American Herbal Products Association's, Botanical Safety Handbook. Boca Raton, FL: USA: CRC Press; 1997. p. $1-51$.

11. Ranganna S. Manual of analysis of fruits and vegetables product. New Delhi, India: Tata McGraw-Hill Publishing Co. Ltd; 1997. p. 29-31.

12. Thimmaiah SR. Standard methods of biochemical analysis. New Delhi, India: Kalyani Publishers; 1999

13. Jackson ML. Soil Chemical Analysis. New Delhi, India: Prentice Hall of India Pvt. Ltd; 1973. p. 67-210.

14. Hesse PR editor. A Textbook of Soil Chemical Analysis. London: John Murray; 1971. p. 255-300.

15. Jha SN, Prasad S. Makhana processing. Agricultural Engineering Today. 1990;14 (3-4):19-22.

16. Boyd CE. Fresh water plants:a potential source of protein. Economic Botany. 1968;22(4):359-368.

17. Shankar Mamta, Neha Chaudhary, Dheer Singh. A review on gorgon nut. International Journal of Pharmaceutical \& Biological Archives. 2010;1(2):101-107.

18. Kumar Lokendra, Gupta VK, Jha BK, et al. Status of makhana (Euryale ferox Salisb.) cultivation in India-Tech Bull. No. R-32/PAT-21 ICARRCER Patna, India; 2011. p. 1-31

19. Kumar Lokendra, Sigh AK, Bhatt BP. Nutritional status of recently developed Makhana (Gorgon Nut) variety - Swarna Vaidehi. Journal of Agri Search. 2016;3(4):199-205.

20. Nath BK, Chakraborty AK. Studies on the Amino acid composition of Euryale ferox salisb. Journal of Food Science and Technology. 1985;22:293.

21. Williams JZ, Abumrad N, Barbul A. Effect of a specialized amino acid mixture on human collagen deposition. Ann Surg. 2002;236(3):369-374.

22. Welbourne TC. Increased plasma bicarbonate and growth hormone after an oral glutamine load. Am J Clin Nutr. 1995;61(5):1058-1061.

23. Bowtell JL, Gelly K, Jackman ML, et al. Effect of oral glutamine on whole body carbohydrate storage during recovery from exhaustive exercise. J Appl Physiol. 1999;86(6):1770-1777.

24. Müller DM, Seim H, Kiess W, et al. Effects of Oral 1-Carnitine supplementation on In Vivo long-chain fatty acid oxidation in healthy adults. Metabolism. 2002;51(11):1389-139.
25. Kendler BS. Supplemental conditionally essential nutrients in cardiovascular disease therapy. J Cardiovasc Nurs. 2006;21(1):9-16

26. Xu Y-J, Arneja AS, Tappia PS, et al. The potential health benefits of taurine in cardiovascular disease. Exp Clin Cardiol. 2008;13(2):57-65.

27. Hansen SH. The role of taurine in diabetes and the development of diabetic complications. Diabetes Metab Res Rev. 2001;7(15):330-346.

28. Bouckenooghe T, Remacle C, Reusens B. Is taurine a functional nutrirent? Curr Opin Clin Nutr Metab Care. 2006;9(6):728-33.

29. Appleton J. Arginine: Clinical potential of a semi-essential amino acid. Altern Med Rev. 2002;7(6):512-522.

30. Castillo L, Chapman TE, Sanchez M, et al. Plasma arginine and citruline kinetics in adults given adequate and arginine-free diets. Proc Natl Acad Sci USA. 1993;90(16):7749-7753.

31. Castillo L, Ajami A, Branch S, et al. Plasma arginine kinetics in adult man: Response to an arginine-free diet. Metabolism. 1994;43(1):114 122

32. Kendler BS. Carnitine: An overview of its role in preventive medicine. Prev Med. 1986;15(4):373-390.

33. Malone JI, Schocken DD, Morrison AD, et al. Diabetic cardiomyopathy and carnitine deficiency. J Diabetes Complications. 1999;13(2):86-90.

34. Mamoulakis D, Galanakis E, Dionyssopoulou E, et al. Carnitine deficiency in children and adolescents with type 1 diabetes. $J$ Diabetes Complications. 2004;18(5):271-274.

35. Rodrigues B, Xiang H, McNeill JH. Effect of L-carnitine treatment on lipid metabolism and cardiac performance in chronically diabetic rats. Diabetes. 1988;37(10):1358-1364.

36. Rodrigues B, Ross JR, Farahbakshian S, et al. Effects of in vivo and in vitro treatment with $\mathrm{L}$-carnitine on isolated hearts from chronically diabetic rats. Can J Physiol Pharmacol. 1990;68(8):1085-1092.

37. Huxtable RJ (1992) Physiological actions of taurine. Physiol Rev 72(1):101-163.

38. Zhang M, Bi LF, Fang JH, et al. Beneficial effects of taurine on serum lipids in overweight or obese non-diabetic subjects. Amino Acids. 2004;26(3):267-271.

39. Menge BA, Schrader H, Ritter PR, et al. Selective amino acid deficiency in patients with impaired glucose tolerance and type 2 diabetes. Regul Pept. 2010;160(1-3):75-80.

40. Duan J, Yin J, Ren W, et al. Dietary Supplementation with L-Glutamate and L-Aspartate Alleviates oxidative stress in weaned piglets challenged with hydrogen peroxide. Amino Acids. 2016;48(1):53-64.

41. Anraku M, Shintomo R, Taguchi K, et al. Amino acids of importance for the antioxidant activity of human serum albumin as revealed by recombinant mutants and genetic variants. Life Sci. 2015;134:36-41.

42. Atmaca G. Antioxidant effects of sulfur-containing amino acids. Yonse Med J. 2004;45(5):776-788.

43. Rahman K. Studies on free radicals, antioxidants, and co-factors. Clin Interv Aging. 2007;2(2):219-236 